\title{
Preparation of carbonated drink from cashew apple juice
}

\author{
A. SOBHANA* and Jose MatheW
}

Cashew Research Station (K.A.U.), Madakkathara, THRISSUR (KERALA) INDIA (Email: sobhakau@yahoo.co.in)

*Author for Correspondence

Research chronicle : Received : 05.11.2014; Accepted : 30.11 .2014

\begin{abstract}
SUMMARY :
Cashew is a major commercial crop of the country with an annual production of nearly 6.5 lakh tons of raw nuts and 50-60 lakh tons of cashew apple. Commercial exploitation of the cashew apple can significantly improve the profitability of cashew growing, as evidenced from the research results of Cashew Research Station, Madakkathara under Kerala Agricultural University. Being a nutritious fruit, the potential for economic utilization of cashew apple is immense as it provides refreshing and healthy drinks. In this context trial was conducted at Cashew Research Station, Madakkathara, for standardizing the preparation of carbonated drink (soda) from cashew apple juice. Cashew apples collected from the field were washed well and juice extracted using juice expeller. The juice was clarified using sago @ 5g/lit. and stored by adding KMS @ $2.5 \mathrm{~g} /$ lit. and citric acid @ 5g/ lit. of juice. Cashew apple soda was prepared from cashew apple syrup. For making cashew apple syrup, one lit. of clarified juice, two kilograms of sugar and $15 \mathrm{~g}$ citric acid were used. Various quantities of the syrup were taken and chilled carbonated water was added to the syrup at different gas pressure. Organoleptic scoring revealed that the sample with 100 psi carbonation in $160 \mathrm{ml}$ chilled water, added to $40 \mathrm{ml}$ cashew apple syrup, thus constituting a total quantity of $200 \mathrm{ml}$ cashew apple soda, was the most acceptable one. This is being filled and sold in $200 \mathrm{ml}$ glass bottles. The carbonated drink has good acceptance among all the consumer segments and large scale production can generate substantial opportunities for income generation
\end{abstract}

KEY WORDS : Cashew apple, Astringency, Clarified juice, Carbonated drink, KMS

How to cite this paper : Sobhana, A. and Mathew, Jose (2014). Preparation of carbonated drink from cashew apple juice. Internat. J. Proc. \& Post Harvest Technol., 5 (2) : 189-191. 